\section{The Crystal Structure of $\beta-\mathrm{CsReO}_{4}$, the Room-Temperature Modification of Cesium Perrhenate}

\author{
Peter Rögner and Klaus-Jürgen Range* \\ Institute of Inorganic Chemistry, \\ University of Regensburg, Universitätsstraße 31, \\ D-W-8400 Regensburg
}

Z. Naturforsch. 48b, 685-687 (1993); received January 11, 1993

Cesium Perrhenate,

Room-Temperature Modification, Crystal Structure

The crystal structure of $\beta-\mathrm{CsReO}_{4}$, the roomtemperature modification of cesium perrhenate, was determined from single-crystal $\mathrm{X}$-ray data as orthorhombic, space group Pnma, $a=5.7556(9)$, $b=5.9964(8), c=14.310(2) \AA$ and $Z=4$.

The structure was refined to $R=0.027, R_{\mathrm{w}}=$ 0.023 for 779 absorption-corrected reflections. It represents an orthorhombic distortion of the tetragonal high-temperature phase $\alpha-\mathrm{CsReO}_{4}$. The structure of $\beta-\mathrm{CsReO}_{4}$ comprises isolated $\mathrm{ReO}_{4}$ tetrahedra, linked together by $\mathrm{Cs}$ ions. The average $\mathrm{Re}-\mathrm{O}$ distance was found to be 1.714(4) $\AA$.

Cesium perrhenate undergoes a reversible phase transition from the room-temperature modification $\beta-\mathrm{CsReO}_{4}$ to a tetragonal high-temperature modification $\alpha-\mathrm{CsReO}_{4}[1,2]$. By means of hightemperature single-crystal X-ray diffraction we recently refined the structure of $\alpha-\mathrm{CsReO}_{4}$ and confirmed the space group to be I $4_{1} /$ amd [3]. Concerning the crystal structure of the room-temperature modification the space group was proposed to be Pnma and the positional parameters of the heavy atoms have been basically determined [4]. Since the atomic co-ordinates of the oxygen atoms remained unknown we decided to investigate this subject.

Cesium perrhenate was synthesized by neutralization of perrhenic acid with cesium carbonate [3]. The precipitated salt was purified by several recrystallizations from water. Single crystals were obtained by slow evaporation of a saturated aqueous solution of $\mathrm{CsReO}_{4}$ at ambient temperature in air.

A colourless transparent crystal (approx. dimensions $0.1 \times 0.07 \times 0.08 \mathrm{~mm}$ ) bounded by $\{112\}$ and $\{001\}$ crystallographic forms was selected for the X-ray investigations. Data collection was performed on an Enraf-Nonius CAD-4 diffractome-

\footnotetext{
* Requests for reprints to Prof. K.-J. Range.

Verlag der Zeitschrift für Naturforschung,

D-W-7400 Tübingen

$0932-0776 / 93 / 0500-0685 / \$ 01.00 / 0$
}

ter using MoK $\alpha$ radiation (graphite monochromator in incident beam). The unit cell parameters were obtained by least-squares refinement based upon 25 carefully centred reflections in the range $8.3 \leq \theta \leq 13.7^{\circ}$. Three standard reflections were measured every $100 \mathrm{~min}$, indicating only random fluctuations in intensity. After reduction of the 1614 recorded data a set of 779 independent reflections with $\mathrm{I}>0 \sigma(\mathrm{I})$ remained of which all were used in the subsequent calculations. Crystallographic and experimental data are summarized in Table I.

Systematic absences of the type $(0 k l): k+l=$ $2 n+1$ and $(h k 0): h=2 n+1$ were observed, agreeing with space groups Pnma and Pn $2_{1}$ a. The results of the structure refinement confirmed the centrosymmetric space group P nma.

All calculations were carried out using the programs SHELX-76 [5] and SHELXS-86 [6]. Atomic scattering factors and corrections for anomalous dispersion were taken from the International Tables for X-ray Crystallography [7].

The structure was solved by Patterson methods, followed by successive difference Fourier synthe-

Table I. Crystal data, data collection and refinement parameters for $\beta-\mathrm{CsReO}_{4}{ }^{\mathrm{a}}$.

\begin{tabular}{ll}
\hline Formula & $\mathrm{CsReO}_{4}$ \\
Molecular weight & $383.11 \mathrm{~g} \cdot \mathrm{mol}^{-1}$ \\
Space group & $\mathrm{Pnma}(\mathrm{Nr} \cdot 62)$ \\
Cell dimensions & $a=5.7556(9) \AA$ \\
& $b=5.9964(8) \AA$ \\
& $c=14.310(2) \AA$ \\
& $\mathrm{V}=493.87(9) \AA^{3}$ \\
$Z$ & 4 \\
Density (calcd) & $5.153 \mathrm{~g} \cdot \mathrm{cm}^{-3}$ \\
$\mu($ MoK $\alpha)$ & $32.0 \mathrm{~mm}^{-1}$ \\
F(000) & 648 \\
Temperature & $297(1) \mathrm{K}$ \\
Radiation & $\mathrm{MoK} \alpha(\lambda=0.71073 \AA)$ \\
Scan mode & $\omega-2 \theta$ \\
Scan width & $\left(0.6+0.35 \mathrm{tan}^{\circ} \theta\right)^{\circ}$ \\
$2 \theta$ range & $4 \leq 2 \theta \leq 60$ \\
$h k l$ limits & $-8 \leq h \leq 8 ; 0 \leq k \leq 8 ; 0 \leq l \leq 20$ \\
(sin $\theta / \lambda)_{\text {max }}$ & $0.7 \AA 0^{-1}$ \\
Recorded reflections & 1614 \\
Unique reflections, $R_{\text {int }}$ & $779,0.027$ \\
Reflections used in & 779 \\
$\quad$ least-squares refine- & \\
ment & \\
Parameters refined & 36 \\
$(\Delta / \sigma)_{\text {max }}$ & 0.001 \\
Weighting scheme & $\mathrm{w}=0.9014 \cdot \sigma^{-2}\left(\mathrm{~F}_{\mathrm{o}}\right)$ \\
Final $R, R_{\mathrm{w}}$ & $0.027,0.023$ \\
$(\Delta \varrho)_{\text {max }}$ min & $+1.0,-1.1 \mathrm{e} \cdot \AA^{-3}$ \\
Extinction coefficient $\mathrm{g}$ & $1.44(1) \cdot 10^{-7}$ \\
&
\end{tabular}

${ }^{a}$ Here, as in the following tables, the standard deviations are given in parentheses. 


\begin{tabular}{lllll}
\hline Atom & $x / a$ & $y / b$ & $z / c$ & $\mathrm{U}_{\text {eq }}$ \\
\hline $\operatorname{Re}$ & $0.03835(6)$ & $1 / 4$ & $0.37984(2)$ & $0.02191(9)$ \\
$\mathrm{Cs}$ & $0.02497(9)$ & $3 / 4$ & $0.12698(3)$ & $0.0297(2)$ \\
$\mathrm{O}(1)$ & $0.822(1)$ & $1 / 4$ & $0.0838(4)$ & $0.038(2)$ \\
$\mathrm{O}(2)$ & $0.856(1)$ & $1 / 4$ & $0.4737(5)$ & $0.056(3)$ \\
$\mathrm{O}(3)$ & $0.0122(8)$ & $0.5154(8)$ & $0.6859(3)$ & $0.049(2)$ \\
\hline
\end{tabular}

Table II. Atomic positional parameters and displacement factores $\left[\AA^{2}\right]$ for $\beta$-CsReO $\mathrm{C}_{4}$. Fractional atomic co-ordinates and equivalent isotropic displacement parameters ${ }^{\mathrm{a}}$.

Anisotropic displacement factors

\begin{tabular}{lllllrl}
\hline Atom & $U_{11}$ & $U_{22}$ & $U_{33}$ & $U_{12}$ & $U_{13}$ & $U_{23}$ \\
\hline $\operatorname{Re}$ & $0.0209(2)$ & $0.0219(2)$ & $0.0229(2)$ & 0 & $-0.0014(1)$ & 0 \\
$\mathrm{Cs}$ & $0.0329(3)$ & $0.0292(3)$ & $0.0271(3)$ & 0 & $0.0067(2)$ & 0 \\
$\mathrm{O}(1)$ & $0.024(3)$ & $0.038(4)$ & $0.051(3)$ & 0 & $-0.008(3)$ & 0 \\
$\mathrm{O}(2)$ & $0.053(4)$ & $0.065(5)$ & $0.050(4)$ & 0 & $0.028(3)$ & 0 \\
$\mathrm{O}(3)$ & $0.053(3)$ & $0.039(3)$ & $0.055(3)$ & $0.014(2)$ & $-0.001(2)$ & $0.017(2)$ \\
\hline
\end{tabular}

${ }^{a} U_{e q}$ is defined as one third of the trace of the orthogonalized $U_{i j}$ tensor.

\begin{tabular}{|c|c|c|c|}
\hline $\begin{array}{r}\mathrm{Re}-\mathrm{O}(1) \\
-\mathrm{O}(2) \\
-\mathrm{O}(3)\end{array}$ & $\begin{array}{l}1.716(6) \\
1.705(7) \\
1.717(5)(2 \times)\end{array}$ & $\begin{array}{l}\mathrm{O}(1)-\mathrm{Re}-\mathrm{O}(2) \\
\mathrm{O}(1)-\mathrm{Re}-\mathrm{O}(3) \\
\mathrm{O}(2)-\mathrm{Re}-\mathrm{O}(3) \\
\mathrm{O}(3)-\mathrm{Re}-\mathrm{O}(3)\end{array}$ & $\begin{array}{ll}110.4(3) & \\
109.1(2) & (2 \times) \\
109.1(2) & (2 \times) \\
110.1(2) & \end{array}$ \\
\hline $\begin{array}{r}\mathrm{Cs}-\mathrm{O}(2) \\
-\mathrm{O}(3) \\
-\mathrm{O}(1) \\
-\mathrm{O}(3) \\
-\mathrm{O}(1) \\
-\mathrm{O}(3) \\
-\mathrm{O}(2)\end{array}$ & $\begin{array}{ll}3.101(7) & \\
3.122(5) & (2 \times) \\
3.142(6) & \\
3.215(5) & (2 \times) \\
3.275(2) & (2 \times) \\
3.578(5) & (2 \times) \\
3.833(4) & (2 \times)\end{array}$ & $\begin{array}{r}\mathrm{Re}-\mathrm{Cs} \\
-\mathrm{Cs} \\
-\mathrm{Cs} \\
\mathrm{Re}-\mathrm{Re} \\
\mathrm{Cs}-\mathrm{Cs}\end{array}$ & $\begin{array}{ll}4.1040(4) & (2 \times) \\
4.2107(4) & (2 \times) \\
4.3387(6) & \\
4.5837(3) & (2 \times) \\
4.5473(7) & (2 \times)\end{array}$ \\
\hline
\end{tabular}

Table III. Selected interatomic distances $[\AA]$ and bond angles $\left[{ }^{\circ}\right]$. ses. After isotropic refinement a numerical correction for absorption was applied to the original data set (program DIFABS, [8]). The final full-matrix least-squares refinement (including anisotropic displacement factors and an extinction correction of the form $\left.\mathrm{F}_{\text {corr }}=\mathrm{F}_{\mathrm{c}}\left(1-\mathrm{gF}_{\mathrm{c}}^{2} / \sin \theta\right)\right)$ converged at $R=0.027$ and $R_{\mathrm{w}}=0.023$. Atomic positions and displacement factors for $\beta-\mathrm{CsReO}_{4}$ are given in Table II, derived atomic distances and angles in Table III*.

The crystal structure of $\beta-\mathrm{CsReO}_{4}$ comprises isolated $\mathrm{ReO}_{4}$ tetrahedra which are linked together by cesium ions. The average $\mathrm{Re}-\mathrm{O}$ distance was found to be 1.714(4) $\AA$. Cesium is tenfold co-ordinated by oxygen with an average $\mathrm{Cs}-\mathrm{O}$ distance of 3.262(4) A. Fig. 1 shows a view of the structure.

* Lists of structure factors, bond distances and bond angles have been deposited at the Fachinformationszentrum Karlsruhe GmbH, D-W-7514 EggensteinLeopoldshafen 2 . Copies may be obtained by quoting the depository number CSD 57083, the name of the authors and literature citation.

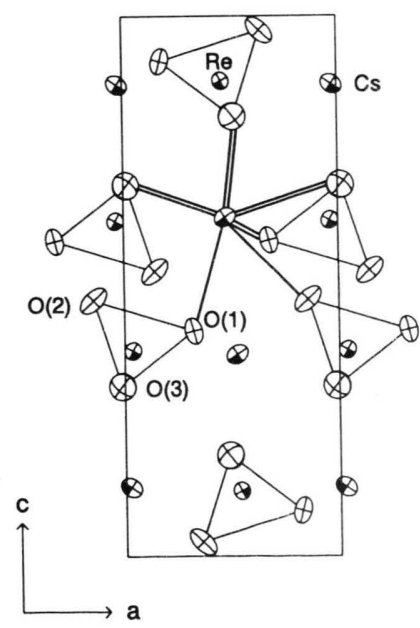

Fig. 1. ORTEP [11] plot of the structure of $\beta$-CsReO ${ }_{4}$. The projection on $(010)$ shows the arrangement of the $\mathrm{ReO}_{4}$ tetrahedra and the co-ordination of one Cs cation. Thermal ellipsoids are scaled to enclose $50 \%$ propability for all atoms. 
The present single-crystal study confirms the space group and the positional parameters of the heavy atoms for $\beta$-CsReO ${ }_{4}$ as proposed by Beintema [4]. $\beta$ - $\mathrm{CsReO}_{4}$ is isomorphous with $\mathrm{CsTcO}_{4}[9]$ and $\mathrm{RbOsO}_{3} \mathrm{~N}$ [10]. It represents an orthorhombic distortion of the tetragonal high-temperature modification $\alpha-\mathrm{CsReO}_{4}$ and is topologically related to the scheelite type as well [3].
The generous support given by the Deutsche Forschungsgemeinschaft (Graduiertenkolleg "Complexity in Solids - Phonons, Electrons and Structures") and the Fonds der Chemischen Industrie is gratefully acknowledged. We thank Dr. U. Klement for the collection of diffractometer data.
[1] B. Kanellakopoulos, J. Inorg. Nucl. Chem. 28, 813 (1966).

[2] H. Beyer, A. Müller, and B. Krebs, Z. Phys. Chem. 234, 423 (1967).

[3] K.-J. Range, P. Rögner, A. M. Heyns, and L. C. Prinsloo, Z. Naturforsch. 47b, 1513 (1992).

[4] J. Beintema, Z. Kristallogr. 97, 300 (1937).

[5] G. M. Sheldrick, SHELX-76. A program for the solution of crystal structures. Univ. of Cambridge, England (1976).

[6] G. M. Sheldrick, SHELXS-86. A program for crystal structure determination, Universität Göttingen (1986).
[7] International Tables for X-ray Crystallography, Vol. IV; The Kynoch Press, Birmingham (1974).

[8] N. Walker and D. Stuart, Acta Crystallogr. A 39, 159 (1983).

[9] G. Meyer and R. Hoppe, Z. Anorg. Allg. Chem. 420, 40 (1976).

[10] P. L'Haridon, R. Pastuszak, and Y. Laurent, J. Solid State Chem. 43, 29 (1982).

[11] C. K. Johnson, ORTEP. Report ORNL-3794. Oak Ridge National Laboratory, Tennessee (1965). 